\title{
The Influence of the Marine Culture on the Architecture in Jiaodong Peninsula
}

\author{
Juan XUE ${ }^{1}$, Chao ZHAN ${ }^{1}$, and Peng SUN ${ }^{1}$ \\ ${ }^{1}$ Shandong Jianzhu University. FengMing Road , Jinan city, Shandong Prov. China
}

\begin{abstract}
With the arrival of the "Era of the Ocean", the coastal city ushered in an upsurge of the development and construction. In order to avoid being lack in the sense of belonging of the coastal city. Implant and deepen marine has become particularly important. This paper firstly has interpreted Marine culture, then analyzed Marine culture formation. Analysis of Marine culture to study the rural settlement. The paper has unearthed Marine culture connotation and characteristics thoroughly, on the basis of the knowledge of Marine culture before, in the Jiaodong building. The paper has carried about the Marine culture on the analysis emphatically to the settlement houses monomer and detail from layout to facade, from construction materials to decorative colors. This paper proposes the renovation of the building, it should carry out traditional marine culture with a view to building on the Jiaodong sustainable development to provide effective guidance, while research and rural settlements is a rich culture and complement. Meanwhile this would be a rich and supplement to research mention on the building.
\end{abstract}

\section{Introduction}

Shandong peninsula is one of the pivotal gateways on Sea Line of Communication of ancient eastern Asia. For thousands of years, Marine culture had got down into bone of the Jiaodong culture and become a main part of it.Residents of Jiaodong adjacent to the sea and rely on it, thus, it formed the unique geographical features and architecture. Wu Liangyong[ Wu Liangyong ${ }^{\mathrm{a}}$, born in 1922 in Nanjing. Chinese Academy of Sciences and Chinese Academy of Engineering academician, Chinese architects, urban planning experts and educators, human settlements science creator.] once said: "culture is the crystallization of history, which retained in the building and together with life. Culture gradually influences the construction of cities and residential behaviors, it becomes the soul of city and architecture." Marine culture gives the unique style of building in Jiaodong area.

Marine culture of Shandong peninsula gives the Jiaodong people hard-working and competent personality. The houses they build combine exquisiteness with practical functions. The seaweed house with warmth and

\footnotetext{
${ }^{\mathrm{a}}$ Wu Liangyong, born in 1922 in Nanjing. Chinese Academy of Sciences and Chinese Academy of Engineering academician, Chinese architects, urban planning experts and educators, human settlements science creator.
}

aesthetics is embodied with the wisdom of residents using local materials. Marine culture produces the Matsu culture which impacts on worship building in Jiao dong district. This article elaborates from the building material, building structure, building layout, architecture color, architectural decoration and construction category and other aspects and expounds the influences of Marine culture on architecture.

\section{Marine Culture and Architecture}

\subsection{The Influence on Architectural Materials}

The selection of architectural materials can reflect local characteristics in the maximum degree. Jiao dong has a temperate and moist climate, encompasses a wealth of mineral resources and abundant flora. The local residents are skilled at selecting local materials and making the most of them. Jiaodong is rich in durable stone which can resist the wind waves. Therefore, stone serves as the common material of building in the Jiaodong area. Foundation is given priority to stone material, mostly, bases with macadam and fills the gap with sand. Walls are finished with stone or mixture brick, from plinth to the eaves is the thick stone walls. The grey tiles and grass are selected to construct roof. The kelp grass roof has the most distinct regional characteristics. Take the seaweed house in Rongcheng as an example to introduce. 
The seaweed house Located in the eastern coastal Tianjintou (sky without horizon) in the easternmost end of Rongcheng City, seaweed house is an unique architectural form. Seaweed house is mainly distributed in the Jiaodong peninsula in Shandong coast, such as Weihai, Yantai, Qingdao. The largest quantity and best preserved sections of seaweed house is in Rongcheng area.

It gets its name by using seaweed grows along the coast of Shandong Peninsula to cover rooftops of the house, and with stones and grey bricks as the wall. Because the seaweed contains a large number of colloid and halogen which can prevent insect and mildew and is not easy to burn, it is the ideal building materials. All materials of traditional seaweed house are sourced locally. Main materials: seaweed, stone, wood, sorghum stalk, and yellow mud. Jiaodong peninsula has humid and rainy summer, fierce windy winter, and it snows a lot in Yantai and Weihai. After strong overlying, the seaweed has good heat preservation and strong wind resistance, it is significantly better than other kinds of tile-roofed houses.

\subsubsection{The seaweed house}

Located in the eastern coastal Tianjintou (sky without horizon) in the easternmost end of Rong cheng City, seaweed house is an unique architectural form. Seaweed house is mainly distributed in the Jiaodong peninsula in Shandong coast, such as Weihai, Yantai, Qingdao. The largest quantity and best preserved sections of seaweed house is in Rongcheng area.

It gets its name by using seaweed grows along the coast of Shandong Peninsula to cover rooftops of the house, and with stones and grey bricks as the wall. Because the seaweed which contains a large number of colloid and halogen can prevent insect and mildew and is not easy to burn, it is the ideal building materials. All materials of traditional seaweed house are sourced locally. Main materials: seaweed, stone, wood, sorghum stalk, and yellow mud. Jiaodong peninsula has humid and rainy summer, fierce windy winter, and it snows a lot in Yantai and Weihai. After strong overlying, the seaweed has good heat preservation and strong wind resistance, it is significantly better than other kinds of tile-roofed houses.

\subsection{The Influence on Architectural Structure}

Due to the affection of perennial damp Marine monsoon, air humidity in Jiaodong coastal areas is big, and it is the damp-proof which is very important to construction. The building is commonly built with high base and high threshold. To withstand wind and rain in summer Yingshan Roof is chosen, because its short depth and big slope is conducive to drainage. With gentle rolling hills local residents effectively use the natural resources to form the structure system of the mixture brick (stone) with wood.

\subsection{The Influence on Architectural Layout}

The main housing type in Jiaodong coastal area is courtyard whose core is the yard, and therefore courtyard residence has become the major kind of Jiaodong coastal residences. The courtyard in Jiaodong is very different from the courtyard in Beijing, houses instead of corridors are around the courtyard which save on the layout, there is only a yard in the middle without front yard and backyard. Due to the influence of the temperate zone monsoon climate, the dwelling houses in coastal area have closed wall and broad courtyard. Closed exterior wall is for escaping the seasonal winds, especially the north wind from the sea in cold winter. In the meantime, it is to strengthen security and construction strong privacy living environment. The open courtyard strives for sunshine as much as possible to resist the damp environment in the coastal areas.

\subsection{The Influence on Architectural Color}

Under the influence of sea cold color, the color of buildings in Jiaodong are black which is the characteristics of Marine culture. Black is the color of water in the Wuxing (five elements). It is clearly that the local people are advocate of the sea from this kind of color tendency. In addition to black, buildings mainly are in cold color. As the basic building material, brick reflects the decorous feeling of nature. At the same time, it always uses the nature color of the material, which includes white, grey and light brown.

\subsection{The Influence of the Building Decoration}

The ancient ancestors in the coastal areas lived by fish and hunt, relying on water draft. So formation of architectural decoration in the Jiaodong area and Marine culture are bound together inextricably. The adornments are fish, dragons etc, with obvious local characteristics.

It is often applied to the Kui dragon pattern in large houses and the corresponding Kui phoenix design. They are commonly used in the ridge, the end of vertical ridges, image wall etc. This kind of Kui dragon pattern which is abstract is very popular in Jiaodong coastal residents building.

What often appears in construction of decoration pattern is fish, turtle, shrimp, crab and other aquatic animals, as well as aquatic plants like seaweed. In a high level of construction, the dragon, fish, seaweed and other image in connection with the sea can be seen everywhere. It makes all kinds of image lifelike through the color processing. It all can reflect the Marin culture widespread influence of the building decoration in Jiaodong region. In addition to the applied animal and plant pattern, the myths and stories on eight immortals are also widely used which reflect the unique style and features of coastal areas. 


\section{Inheriting Marine Culture to Realize the Sustainable Development of Jiao dong Architecture}

Nowadays, the sustainable development strategy has become a global program of action. At the same time, the globalization has created new opportunities and challenges for the development of architecture. However, the process of globalization is at the expense of the sacrifice. Fast-food culture is corroding national culture in people' $s$ heart. Local characteristics are damaged. In gradually fading of particularity and losing of national tradition, we need to find a suitable architecture with the regional characteristic cultural ecology of the organic update strategy, in order to realize the sustainable development of regional architecture.

\subsection{The Principle of Realizing the Sustainable Development of Jiao dong Architecture}

Thus, how can architecture realize the development trend in today' s society? It relies on people, architecture and natural environment building a reasonable relationship of supplementing each other and mutual promotion, to achieve the harmony of the three. So we must follow certain principles:

\subsubsection{The Principle of Continuity}

The principle of continuity emphasizes the continuity of culture first of all. Usually, the development of economic in inland less rapid than coastal areas which echoes the profound history and culture. At the same time, the transportation is so convenient that the foreign cultural exchange frequently. In the local indigenous culture and foreign culture collision exchange, it gradually formed a composite, the freedom of open Marin culture. So, how does architecture in the coastal areas of Jiaodong explore and inherit the history in the process of organic update, how to protect and continue the Marine culture, how to guide, control and create maritime architectural form and symbol, all of them are the new task to build a new socialist countryside.

\subsubsection{Ecologic Principle}

We should take the concept of sustainable development in the sustainable development of architecture, promote the common development of both, create organic architecture which can be integrated with environment and put forward the "zero energy consumption". The purpose of architectural design is to adapt to the ecological environment. Architectural design not only has minimum assault to environment, but also can effectively utilize renewable resources and reduce energy consumption. Only in this way can we build a healthy, high-level and pleasant indoor environment. Therefore, environmental protection and the realization of sustainable development of architecture can' t be done without the concept of ecological architecture. It will become the inevitable trend of building development.

\subsubsection{Characteristic Principle}

The unique topography and climate conditions of Jiaodong region provide different natural and geographical backgrounds for the formation of characteristics of the coastal architecture in Jiaodong. Therefore, when we organically update coastal buildings of Jiaodong area, we should pay attention to excavate and shape their own characteristics, fully reflect and strengthen natural features of the sea, rather than copy the rigid design model of a new socialist countryside.

\subsubsection{Re-use Principle}

There is abundant marine cultural information in the coastal architecture of Jiaodong, which is to be used reasonably and updated in the process of buildings transformation. Certain building materials are energy which can be recycled and original, like adobe; tiles and rocks of masonry wall can be reused; wrack, as building materials of the roof, was taken from the nature and should be returned to nature and so on. The principle that we reasonably reuse them not only can save cost, but also can create unexpected results.

\subsection{Positioning}

Place the figure as close as possible after the point where it is first referenced in the text. If there is a large number of figures and tables it might be necessary to place some before their text citation. If a figure or table is too large to fit into one column, it can be cantered across both columns at the top or the bottom of the page.

\subsection{Color illustrations}

You are free to use color illustrations for the online version of the proceedings but any print version will be printed in black and white unless special arrangements have been made with the conference organizer. Please check with the conference organizer whether or not this is the case. If the print version will be black and white only, you should check your figure captions carefully and remove any reference to color in the illustration and text. In addition, some color figures will degrade or suffer loss of information when converted to black and white, and this should be taken into account when preparing them.

\section{Conclusions}

When a kind of culture is generally regarded as the "traditional culture", it means that it has gone through a long time and accumulated deep emotion. It becomes a kind of spirit being stationed in people's hearts and makes people admire, miss and even hard to forget. People develop and improve traditional architectural form by making the essence of national culture into it. This paper organically combines the Marine culture with the architectural features of Jiaodong coastal areas. By studying the influence of Marine culture of Jiaodong region on construction, this paper explores the sustainable 
development of traditional buildings and the present situation of the Marine cultural heritage in the region, enriches and develops the traditional architectural culture and Marine culture.

\section{Acknowledgements}

First and foremost, I appreciate my country who give me a comfortable learning atmosphere. Second, I would like to show my deepest gratitude to my supervisor, Prof. Juan XUE, who has walked me through all the stages of the writing of this thesis. Without her illuminating instruction and patience, this thesis could not have reached its present form.

\section{References}

1. Qu Jinliang: A Marine Culture and Society, China Ocean University Press. (2003)

2. Sun Yun-long: Of Shandong House, Shandong Wenhua Yinxiang Press. (1999)

3. Luo Chunrong: The Matsu Legend Study-A Maritime Power of Myth, Tianjin Ancient Books Press. (2009)

4. Bo Xinhua, ZhaiXin and Li Longsen : Shandong Ocean Cultural Characteristics of the Formation and Development, Xi'an Jiaotong University Press. (2010)

5. M.A.Li Zheng: Jiaodong Traditional Tousesand Modern Interpretation, Tianjin University. ( 2003)

6. Zhao Gang: Regional Culture Return and Architectural Features of the Re-creation, Huazhong Architecture. (2001)

7. You Shaoping, Chang Xingzhao: Building, Shandong Friendship Press. (2002)

8. Sun Fenghua ,Wei Xiao: House, Shandong Friendship Press. (2004) 